\title{
DOCENTES DE CURSOS DA ÁREA DA SAÚDE: \\ O PAPEL DA DIDÁTICA NA FRONTEIRA PROFISSÃO/PROFESSOR
}

\author{
TEACHER OF HEALTH SCIENCES UNDERGRADUATION: THE \\ ROLE OF DIDACTICISM IN THE FRONTIER OF PROFESSION \\ AND PROFESSOR'S ACTIVITIES
}

\section{DOCENTES DE CURSOS DE LA ÁREA DE LA SAÚDE: EL PAPEL DE LA DIDÁTICA EN LA FRONTERA DE LA PROFESIÓN/ PROFESOR}

\footnotetext{
Reginaldo Almeida da Trindade ${ }^{1}$

Universidade Federal do Rio de Janeiro, Professor da Faculdade de Farmácia

Renata de Mendonça Campos ${ }^{2}$

Universidade Federal do Rio de Janeiro, Professora do Instituto de Microbiologia Paulo de Góes

Giseli Barreto da $\mathrm{Cruz}^{3}$

Universidade Federal do Rio de Janeiro, Professora do Programa de Pós-graduação em Educação

Monique Andries Nogueira ${ }^{4}$

Universidade Federal do Rio de Janeiro, Professora do Programa de Pós-graduação em Educação na Faculdade de Educação

\begin{abstract}
Resumo: Neste artigo discute-se o papel da Didática no exercício da docência no Ensino Superior no contexto de cursos de graduação da área da saúde. O texto visa suprir uma lacuna na literatura específica sobre as dificuldades e as adaptações necessárias e vivenciadas por docentes desse nível de ensino em cursos da saúde, considerando a comum ausência de formação técnica específica para a docência. Ao discorrer sobre a preparação desses profissionais para ensinar, abordam-se questões relativas ao tec-

${ }^{1}$ Doutor em Biotecnologia pela Universidade de São Paulo; Especializando em Docência na Saúde pela Universidade Federal do Rio Grande do Sul.

${ }^{2}$ Doutora em Microbiologia pela Universidade Federal do Rio de Janeiro; Especializanda em Docência na Saúde pela Universidade Federal do Rio Grande do Sul.

${ }^{3}$ Doutora em Educação pela Pontifícia Universidade Católica do Rio de Janeiro.

${ }^{4}$ Doutora em Educação pela Universidade de São Paulo.
\end{abstract}


nicismo da formação, às definições do Ministério da Educação quanto aos currículos formativos e ao apoio didático-metodológico na elaboração das disciplinas em suas abordagens teóricas e práticas.

Palavras-chave: Didática. Docência no Ensino Superior. Prática docente. Ciências da Saúde.

Abstract: In this paper it was discussed the role of Didactics for the professor's academic career in health undergraduation courses. It aims to fill an observed gap in the specific literature relating difficulties and the needed adaptations experienced by teachers who act in higher education health courses, taking into consideration the common absence of technique-specific knowledge for teaching. By discussing preparation of these professionals for teaching, here we approach the technicism of their formation, the recommendations of the Ministry of Education regarding curriculum of those courses, and the methodological-teaching support in the preparation of disciplines in its theoretical and practical approaches.

Keywords: Didactics. Undergraduation teaching. Teaching practices. Health Sciences.

Resumen: En este artículo se analiza el papel de la Didáctica en la enseñanza en la educación superior en el contexto de los cursos de licenciatura en la área de la salud. El texto tiene como objetivo llenar un vacio en la literatura sobre las dificultades y las adaptaciones necesarias y vivenciadas en la enseñanza superior, en los cursos de la salud, teniendo en cuenta la ausencia de formación técnica especifica común para la enseñanza. Para discutir la preparación de estos profesionales para enseñar, para abordar las cuestiones relativas a la tecnicidad de la formación, las definiciones del Ministerio de Educación sobre los programas de formación y apoyo de enseñanza-metodológico en la elaboración de disciplinas en sus enfoques teóricos y prácticos. Palabras clave: Didáctica. Enseñanza en la Educación Superior. Práctica docente. Ciencias de la Salud.

\section{INTRODUÇÃO}

Este texto foi pensado a partir da necessidade observada pelos autores de que há poucos trabalhos na literatura específica abordando as dificuldades enfrentadas e as adaptações necessárias e vivenciadas pelos professores do Ensino Superior nos cursos de graduação da área da saúde, os quais muito comumente não tiveram forma- 
ção didática para o exercício da docência ao longo de sua trajetória profissional. Para exemplificar essa situação, no trabalho de Silva e Alencar (2010), desenvolvido com um grupo de professores de cursos da área da saúde de uma instituição do Distrito Federal, os resultados apontam que aproximadamente $50 \%$ dos docentes relataram nunca haver tido contato com disciplinas didático-pedagógicas ao longo de toda a formação. Nesse aspecto, é possível direcionar essa problemática às carreiras tradicionais da Medicina, Enfermagem, Fonoaudiologia, Odontologia, Nutrição, Fisioterapia, Biomedicina e Farmácia, pois são cursos cujas grades curriculares obrigatórias não contemplam a formação didática. Ainda há outras, como a Educação Física, a Psicologia ou a Terapia Ocupacional, que, por características peculiares à própria formação ou ao exercício da profissão (por exemplo, a licenciatura em Educação Física ou a Psicologia), oferecem ao aluno contato com disciplinas didático-pedagógicas ao longo da graduação. Há também o bacharelado em Ciências Biológicas, uma área correlata, que, quando complementado com a licenciatura, oferece enfoque para a formação didática. No decorrer da pesquisa bibliográfica para a redação deste artigo, na qual se utilizaram como estratégia de busca na internet os termos "prática docente + enfermagem", sendo o segundo termo substituído sequencialmente pelas demais profissões, foi constatado pelos autores que, entre os cursos específicos da saúde, o Curso de Enfermagem é o que possui a maior quantidade de trabalhos publicados na literatura específica avaliando as práticas docentes adotadas pelos professores do referido Curso.

Estudos sobre a formação do professor universitário, particularmente das áreas tecnológicas, apontam que no Brasil esse processo ocorre, na grande maioria das vezes, por meio de uma construção individual, em que a prática pedagógica é pautada na repetição de experiências vividas durante as etapas escolares anteriores, sem que o indivíduo tenha tido contato com as ciências relacionadas aos processos de ensino e de aprendizagem como a Pedagogia (CASTANHO, 2002). No contexto da formação direcionada aos aspectos técnicos, muitas vezes, em detrimento dos aspectos humanistas, também necessários ao desenvolvimento de qualquer profissional e não apenas a quem se dedica à docência, Cunha (2006, p. 358) relata:

\footnotetext{
A formação do professor universitário tem sido entendida, por força da tradição e ratificada pela legislação, como atinente quase que exclusivamente aos saberes do conteúdo de ensino. Espera-se que o professor seja, cada vez mais, um especialista em sua área, tendo-se apropriado, com o concurso da pós-graduação stricto sensu, do conhecimento legitimado academicamente no seu campo científico. O domínio do conteúdo,
} 
por sua vez, deve ser alicerçado nas atividades de pesquisa que garantam a capacidade potencial de produção de conhecimento.

A concepção descrita anteriormente toma forma durante os próprios processos de seleção de professores e a eleição dos critérios de avaliação das universidades. Sem exceção para os cursos da área da saúde, o fator definidor para a seleção de professores se baseia, quase que exclusivamente, na competência técnica, no desempenho profissional, na atuação em pesquisa e na produção científica gerada. Uma vez estabelecido o novo vínculo de professor, principalmente nas universidades públicas, o desempenho profissional continua sendo valorizado de acordo com essa mesma produção científica. $\mathrm{Na}$ área da saúde esse prestígio está diretamente relacionado às publicações em periódicos e participações em eventos científicos qualificados. A atuação em cursos de pós-graduação apresenta maior valor agregado, e o exercício do ensino na graduação, em contrapartida, aparece como uma continuação das demais atividades. Somados às exigências anteriormente descritas, os cursos de graduação passaram a ter a qualidade medida, principalmente, por meio de provões de ingresso e/ou egresso, como o Exame Nacional de Desempenho dos Estudantes (Enade). Essa sistemática incorre no viés de direcionar o ensino para a obtenção do sucesso no sistema avaliativo aplicado, em detrimento de uma abordagem formativa mais ampla requerida para a garantia de eficiência de um profissional, principalmente na área da saúde. Essa tendência é também definida por Cunha (2006) como uma educação com caráter neotecnicista. O Ministério da Educação já vem sinalizando estratégias para avaliar a eficiência de um bom desempenho acadêmico pelo Enade e a questão da empregabilidade desses egressos avaliados por meio da Pesquisa Nacional sobre Egresso e Perfil de Empregabilidade - ENADE, cuja divulgação dos primeiros resultados estava prevista para o ano 2015 (MINISTÉRIO DA EDUCAÇÃO, 2014).

Dessa forma, a pressão das exigências em pesquisa e desenvolvimento tecnológico e a ausência de saberes específicos na relação entre ensino e aprendizagem resultam em uma diminuição de reflexão, por parte dos professores, sobre as suas práticas pedagógicas e sobre a qualidade do ensino universitário. Para atender a uma demanda cada vez maior, o professor da área da saúde opta, na maioria das vezes, por aulas expositivas na forma de monólogos, nas quais a dinâmica se restringe à transferência de conceitos, informações e experiências adquiridas nas suas áreas de atuação científica, objetivando tão somente que os alunos absorvam e retenham o conhecimento para a reprodução nas avaliações periódicas. Dentro dessa estrutura, o professor é o único sujeito da ação, pois seleciona o conteúdo, transmite, informa, orienta e avalia. 
O aluno torna-se um receptor passivo no seu processo de formação, reagindo apenas de acordo com alguma solicitação do professor.

Esse método monólogo-autoritarista, verticalizado, repetido por diversos anos, tem sido o responsável pela formação de muitos profissionais nas últimas décadas, ainda que diversos movimentos em favor de sua revisão ocorram de tempo em tempo, em razão da complexidade crescente da sociedade. Parte dessa resistência pode ser atribuída à grande dificuldade dialógica entre os campos, como as ciências exatas, humanas, biológicas e da saúde, e outra parte pode ser atribuída à autonomia institucional e departamental de que gozam as diferentes unidades acadêmicas, tornando o processo de ensino, ainda que dentro de uma mesma instituição, individualizado em termos de cursos. O que tem sido possível observar é que o corpo discente, principalmente nas universidades públicas, apresentava um grau maior de homogeneidade há alguns anos, isto é, era composto por alunos com qualidade de ensino comparável nas etapas fundamental e intermediária. Atualmente, com a proposta de universalização do ensino superior, sem o devido acompanhamento da qualidade do ensino básico e fundamental, a universidade apresenta um cenário bastante diverso.

Essa mudança é resultante das políticas atuais de ingresso no Ensino Superior, como a adoção do Exame Nacional do Ensino Médio (ENEM) como requisito para a entrada nas universidades, a seleção por meio do Sistema de Seleção Unificado (Sisu) e o estabelecimento do sistema de cotas, que vêm contribuindo para uma população heterogênea na universidade.

O corpo discente passou a ser composto por alunos de várias regiões do País, de diferentes classes sociais, portanto, com diferentes backgrounds educacionais. Sem entrar no mérito de que essa heterogeneidade pode gerar inúmeros benefícios para a sociedade, como uma maior compreensão das necessidades regionais e a integração das classes, o fato é que tais benefícios não podem ser acompanhados de uma perda da qualidade na formação do profissional. Além disso, o professor universitário se vê diante de novo problema ou dilema educacional quanto à condução do seu exercício profissional.

Encoberto por essas mudanças há um grande desafio para os docentes do Ensino Superior, ou seja, não perder, mas, sim, aumentar a qualidade do ensino. E dentro desse cenário a especialização conteudista, por si só, não consegue trazer todas as ferramentas necessárias para uma reflexão e reconstrução da prática de ensino em atenção à demanda. Essa reflexão somente pode surgir a partir da compreensão da prática, dos "saberes" mobilizados pelos envolvidos (docentes e alunos) na geração do conhecimento no ambiente da sala de aula. 
Dentro da busca de conceitos que podem contribuir para a reflexão das atividades na sala de aula, cabe mencionar as definições de Masetto (2003, p. 82) sobre ensino e aprendizagem. Segundo esse autor: "Quando falamos em aprendizagem estamos nos referindo ao desenvolvimento de uma pessoa, e no nosso caso, de um universitário nos diversos aspectos de sua personalidade." Dentro do desenvolvimento descrito pelo mesmo autor, ressaltam-se as habilidades " [...] de raciocinar, de refletir, de buscar informações, de criticar, de dar significado pessoal às novas informações adquiridas, de relacioná-las, de pesquisar e de produzir conhecimento.” (MASETTO, 2003, p. 82).

Nesse conjunto de habilidades desenvolvidas pelo futuro profissional, na área da saúde, a identidade humanística também não pode ser esquecida, pois ela contribuirá para a qualidade das ações. Dessa forma, cabe aos docentes uma reflexão e autocrítica sobre o posicionamento dos seus alunos durante a sua prática pedagógica, bem como sobre os benefícios de retirá-los da posição de receptores para coclocá-los na posição de construtores das suas habilidades e do seu próprio conhecimento.

Portanto, a seguir, são abordados alguns aspectos relacionados ao desenvolvimento didático de professores que adentram a sala de aula sem formação específica para o ensino e que, por força do ofício, desenvolvem-se na prática docente.

\section{A FORMAÇÃO TECNICISTA}

O profissional graduado nos cursos do campo da saúde em alguma das áreas anteriormente citadas possui, ao longo da sua graduação, eixos formativos, que de forma generalista, compreendem um eixo básico, no qual são ministradas disciplinas comuns às áreas da saúde, como anatomia, fisiologia, biologia celular, entre outras, e um eixo formativo, que compreende a formação técnica específica de cada curso. Nesse caso, é possível citar exemplos de disciplinas como Técnica cirúrgica para o Curso de Medicina, Farmacotécnica para o Curso de Farmácia, Técnicas laboratoriais de diagnóstico para o Curso de Biomedicina, Técnica dietética para o Curso de Nutrição, Reabilitação funcional para o Curso de Fisioterapia e assim por diante. Dessa forma, "A organização do currículo tradicional, na maior parte dos cursos superiores do Brasil, baseou-se em disciplinas isoladas e estanques, justapostas arbitrariamente, fragmentando e isolando o conhecimento." (BELEI; GIMENEZ-PASCOAL; NASCIMENTO, 2008, p. 106).

E, sob esse ponto de vista, verifica-se que, na área da saúde, grande parte das instituições ainda possui e mantém essa estrutura formativa. 
O que se tem visto, principalmente em algumas instituições de maior porte, mais especificamente nas universidades estaduais e federais, particularmente aquelas formadas por institutos independentes, é certa liberdade para que os alunos possam cursar disciplinas eletivas ou de livre escolha, e dentro destas, é possível optar por alguma com enfoque didático-pedagógico. Outro aspecto importante quanto à grade curricular dos cursos de graduação da área da saúde diz respeito às normatizações e requisitos mínimos para a sua constituição. Esses itens estão contidos nas Diretrizes Curriculares Nacionais (DCNs) que, em sua maioria, preconizam uma formação generalista, humanista, crítica e reflexiva para atuar dentro de um contexto assistencialista (ALMEIDA et al., 2007). Essas mudanças foram geradas a partir da criação do Sistema Único de Saúde (SUS) no Brasil, que forçou as escolas da saúde a revisarem seus conteúdos e metodologias aplicadas aos processos de ensino e de aprendizagem dentro de um contexto integralista.

Essa integralidade pode ser abordada sob dois panoramas distintos: o primeiro trata da multidisciplinaridade da equipe profissional que é preconizada pelas novas políticas do SUS, e o segundo trata do aspecto educacional no sentido de repensar quais as formas de aplicação dessas metodologias de integração na formação do novo profissional da saúde. Essa segunda ênfase é discutida por Ceccim e Feuerwerker (2004), que abordam o papel da educação no sentido didático-formador, na adaptação das escolas da saúde em direção à autocapacitação e na formação de profissionais articulados às necessidades sociais da saúde e, também, ao sistema de saúde vigente no País. Sob esse aspecto, nos anos 2000 e 2001, ainda à época das reformas e da criação das novas DCNs, houve uma mobilização estratégica de grande parte das profissões para que fossem aprovadas mudanças importantes nos projetos político-pedagógicos dos cursos. Entre os de maior destaque estão aqueles que contemplam as novas abordagens metodológicas de ensino, visando a uma formação problematizada na realidade vivida pelo profissional. Isso permitiu uma maior abertura à aplicação e à ampliação do então "Ensino baseado em problemas" ou $P B L$, do inglês Problem Based Learning (ALMEIDA; BATISTA, 2013). Outra mudança importante, ainda que anterior, foi a tentativa de introduzir no Ensino Superior as práticas que já vinham sendo aplicadas no Ensino Básico e Fundamental, a partir da nova Lei de Diretrizes e Bases (LDB) da Educação Nacional (BRASIL, 1996), ou seja, o ensino centrado no estudante ou o "graduando" no protagonismo ativo nos processos de ensino e de aprendizagem, no contexto da escola progressista, considerando, ainda, o interacionismo proposto pela Psicologia da Educação no campo da Didática (LIBÂNEO, 2012). Em uma supradimensão, essas intervenções procuraram definir o papel 
de cada parte, ou seja, o professor como mediador e intervencionista, e o aluno como sujeito ativo nesse processo.

A partir disso, muitos projetos foram criados e continuam sendo gerados pela articulação do Ministério da Educação, com seus subórgãos, e o Ministério da Saúde, com o objetivo maior de subsidiar e auxiliar os docentes nessa nova perspectiva formativa de integração da realidade vivida coadunando com o SUS no País, principalmente considerando o grande aumento no número de docentes contratados nas instituições federais de ensino superior a partir do Programa de Apoio a Planos de Reestruturação e Expansão das Universidades Federais (Reuni), criado em 2007. Para exemplificar, pode-se citar o Educasaúde, um projeto no qual:

[...] atividades de pesquisa envolvem o estudo e investigação de temáticas na interseção entre a Educação e Ensino da Saúde, ocupando-se da formação interdisciplinar e intersetorial dos profissionais de saúde nas áreas da Educação e da Saúde Coletiva. (EDUCASAÚDE, 2015).

Portanto, observa-se que sob esse prisma, muitas iniciativas foram criadas e estão em andamento para que se atinjam e se fortaleçam as novas diretrizes preconizadas na formação do profissional da saúde em relação ao seu exercício no âmbito social. Entretanto, permanece uma lacuna importante no processo: quais conhecimentos deve o professor mobilizar para que possa desempenhar seu papel de forma satisfatória para a instituição de ensino, para os seus alunos e para si mesmo?

A Pedagogia e a Didática representam processos de formação. Especifica-se, nesse caso, o Brasil, porque, segundo Pimenta e Anastasiou (2010), nos países mais avançados já há uma preocupação crescente com a formação e o desenvolvimento dos professores universitários sob os aspectos da qualidade do ensino, novas tecnologias, direitos e liberdades dos profissionais e as condições de trabalho, que começaram a ser discutidas a partir de 1997 na Conferência Internacional sobre Ensino Superior - uma perspectiva docente, em Paris. A docência no Ensino Superior, particularmente nos cursos de caráter mais técnico, como é o caso dos cursos da saúde, é extremamente complexa, porque obriga o relacionamento próximo entre a profissionalidade, como exercício da profissão-base de formação, e a pedagogia, o que não é uma tarefa trivial. 


\section{A DICOTOMIA PROFESSOR/PROFISSIONAL}

O professor do Ensino Superior, salvo raras exceções, por não possuir formação específica em Didática, desenvolve sua atividade docente baseada em três informações: a intuitiva, que é construída a partir do seu conhecimento a respeito da disciplina e daquilo que se faz necessário ser transmitido por ela; a autodidata, pela criação de estratégias que acredita serem adequadas para trabalhar o conteúdo; por fim, e talvez a mais importante e influente no processo, que é a observação e o seguimento dos seus próprios mestres e professores. Em outras palavras, tomam-se como exemplos aqueles docentes que tiveram forte influência, seja boa, seja má, sobre sua própria formação, e busca-se reproduzir as boas características em relação à maneira de ensinar o conteúdo necessário e abster-se das más características. Conforme abordado e definido por Castanho $(2001,2002)$ como derivações do "professor marcante", destacamos: esse professor utiliza diferentes ferramentas didáticas além da aula expositiva; conhece bem sua área de atuação e, assim, consegue ensinar e adaptar o ensino aos diferentes contextos; planeja antecipadamente suas aulas; alia a afetividade da relação aluno-professor à capacidade cognitiva; une o conteúdo teórico à futura prática profissional do aluno em uma contextualização social; entre outras.

Não se pode e nem se deve desconsiderar essa influência "modelo" como uma importante ferramenta construtiva da forma pessoal de desenvolver a atividade docente, mas sendo essa atividade uma prática dinâmica, na maior parte das vezes, a busca do aperfeiçoamento e do acompanhamento desse dinamismo da atividade fica em segundo plano. O que se quer dizer é que, se tomarmos como exemplo um professor com títulos de mestrado e doutorado, o espaço de tempo ocorrido entre o indivíduo enquanto aluno e, posteriormente, como professor, é de oito a 12 anos, considerando quatro anos de graduação, dois anos de mestrado e quatro anos de doutorado, em média. E, em razão da velocidade das mudanças proporcionadas pela informatização atualmente, esse não é um espaço de tempo que pode ser negligenciado, particularmente na área das ciências biológicas e da saúde. Portanto, a atividade docente é uma prática dinâmica sob muitos aspectos.

O primeiro desses aspectos está relacionado ao público-alvo. Não se pode dizer ou querer que os alunos mantenham seus aspectos ou que eles sejam imutáveis em suas características discentes ao longo da carreira de um professor. Exemplificando esse conceito, basta-se comparar o corpo discente no cenário da graduação dos anos 1980 e 1990, com o início da informatização, com os graduandos dos anos 2000 em diante, com a universalização da informação por meio da internet, e ainda mais 
recentemente com o avanço do acesso à rede mundial por meio da telefonia móvel, que permite uma interação quase simultânea, por exemplo, entre o que está sendo ensinado e o que é vivido na prática profissional. Sem dúvida, tais transformações estão em voga na prática docente e são alvos de muitos estudos e discussões em termos didático-pedagógicos, e, por outro lado, como talvez já tenham sido vivenciadas por parte dos leitores deste texto, têm feito surgir alguns conflitos no ambiente da sala de aula.

O segundo aspecto está relacionado ao avanço tecnológico específico de cada área. Podemos citar, mas não dimensionar, o impacto gerado pelos avanços científicos dos últimos 20 anos no conteúdo curricular e disciplinar obrigatório dos cursos da área da saúde, como a cirurgia a laser e guiada por vídeos, técnicas de diagnóstico por tomografia computadorizada, moléculas radiomarcadas para diagnóstico de lesões teciduais, a nanotecnologia farmacêutica, os alimentos funcionais, a automação nos laboratórios médicos, apenas para elencar alguns entre muitos outros avanços. Embora os conceitos básicos mudem com uma velocidade menor por força da sua natureza de suporte, tudo que é construído a partir deles sofre alterações drásticas por efeito das novas descobertas da ciência praticamente a cada dez anos. Algumas técnicas e procedimentos são totalmente superados por novas tecnologias e/ou novas aplicações. $\mathrm{Na}$ área da saúde e também nas das engenharias, a ocorrência desse fenômeno é vista em uma velocidade muito maior do que talvez ocorra em outras áreas, como as áreas humanas, por exemplo, em que algumas mudanças dependem do acompanhamento de transformações culturais de uma sociedade, sendo um processo muito mais lento.

Por ser o professor da área da saúde um profissional de atividade dicotômica, que tem sua prática baseada não somente no conhecimento e exercício prático, mas também na forma de trabalhar esse conhecimento de modo compreensível, adaptado, adequado e didático para formar outros profissionais, não é rara a existência de muitas dúvidas e conflitos em relação a como coadunar toda essa gama de habilidades necessárias ao exercício da profissão professor.

Algumas questões em relação à prática docente permanecem em aberto, e buscaremos abordar de modo sistematizado algumas delas a partir desse ponto. São questões relacionadas ao papel ou função de cada elemento ou metodologia pedagógica dentro da sala de aula de um curso, cujo objetivo do ensino seja prioritariamente voltado aos aspectos técnicos. De forma contextualizada ao ambiente do ensino nos cursos da área da saúde, é discutido o papel da aula expositivo-teórica e da aula prática. Essas são as principais estratégias metodológicas usualmente aplicadas no desen- 
volvimento de uma disciplina de graduação nos cursos da área da saúde nas principais instituições de ensino do País.

\subsection{AULAS EXPOSITIVO-TEÓRICAS}

Segundo Lopes (2001), a aula expositivo-teórica por definição é considerada uma "[...] técnica de ensino padrão da Pedagogia Tradicional." Ela é basicamente centrada na figura do professor como transmissor do conhecimento de forma verbalizada, em que, frequentemente, não se dá oportunidade de participação ativa aos ouvintes, e o conhecimento transmitido durante o discurso segue praticamente sem questionamentos na maior parte do tempo. Apesar de essa metodologia não ir ao encontro de quase nenhum dos requisitos mínimos das práticas pedagógicas modernas, permanece como a preferida por todos os envolvidos no processo educativo, professores e alunos. No trabalho de Rozendo (1999), que analisou as práticas docentes especificamente dos professores de cursos de graduação em saúde em diversas universidades públicas e privadas, foi detectado que até $85 \%$ dos docentes utilizam a aula expositiva como método de ensino mais frequente em suas disciplinas. Soares (2006) relata, em sua pesquisa com professores da Faculdade de Ciências Médicas da Universidade Estadual do Piauí, os quais ministram disciplinas para os Cursos de Medicina, Enfermagem, Fisioterapia e Psicologia, que 100\% dos participantes utilizam a metodologia das aulas expositivas e, dentro destas, discussão de casos e trabalhos dirigidos em grupos. O que torna esses dados preocupantes é que, mesmo sendo uma faculdade de cursos da saúde, com caráter de formação técnica, apenas 13\% relataram utilizar aulas práticas de laboratório ou em clínicas ao longo de suas disciplinas.

$\mathrm{Na}$ área da saúde as aulas expositivas ainda têm uma função primordial na transmissão dos conceitos básicos que estão atrelados à construção do conhecimento em um determinado assunto. Nesse aspecto, abordam-se as definições, o histórico, a importância do assunto, a aplicação prática e, algumas vezes, a sua interação com o curso em questão ou com outras disciplinas. Como exemplo, pode-se citar o ensino de fisiologia, que é uma disciplina básica e comum a praticamente todos os cursos da saúde.

O ensino de fisiologia aborda o funcionamento dos diversos sistemas que suportam o funcionamento do organismo, como os sistemas digestório, circulatório, respiratório, nervoso, etc. A maior parte da explicação do funcionamento desses sistemas é realizada de modo expositivo por meio de aulas teóricas com o auxílio de ferramentas didáticas, ou seja, esquematizações, figuras, gráficos, etc. Durante essas aulas, o 
professor atua como um "explicador" dos conceitos abordados em livros e textos, que são escritos para todos os públicos, buscando alternativas figuradas e adaptações para transmitir determinado conhecimento dentro do contexto daquele público específico. $\mathrm{O}$ papel do professor na aula expositiva integra, relaciona, adapta (aprofunda, expande ou sintetiza) o conhecimento para a realidade do seu público, ou seja, é a contextualização inicial do conteúdo abordado.

Essas três tarefas citadas (integração, relacionamento e adaptação) não são habilidades triviais de serem adquiridas. Sob esse ponto de vista, tem-se o papel da didática despertando ou revelando ao professor a necessidade de desenvolver a docência. Segundo Libâneo (2012), “[...] a didática realiza objetivos e modos de intervenção pedagógicos em situações específicas de ensino-aprendizagem." Nesse sentido, a didática estimula e auxilia o professor na organização e na mobilização dos demais saberes necessários à contextualização do ensino, além, obviamente, daqueles inerentes ao domínio do conteúdo, como o conhecimento relacional entre a disciplina e o curso de graduação em questão, mais especificamente ao Projeto Pedagógico do Curso, a relação da disciplina com a prática profissional do profissional egresso, o contexto sócio-histórico-cultural dos alunos, a disponibilidade de recursos didáticos da instituição, etc.

Essas não são questões geralmente vivenciadas e abordadas durante o processo formativo do professor da área da saúde em seus respectivos cursos de especialização profissional, mestrado e doutorado. Nesse ponto, convém ressaltar que, no Brasil, a política do Ensino Superior preconiza que a formação dos professores para esse nível de ensino ocorrerá por meio de cursos de pós-graduação em nível de especialização, mestrado ou doutorado, mas não obriga uma formação didática específica (BRASIL, 1996). A pós-graduação, principalmente "stricto sensu", traz ao aluno, com a prática da pesquisa científica, habilidades relacionadas à função de pesquisador e não de professor. Embora para os bolsistas de mestrado e/ou doutorado da Coordenação de Aperfeiçoamento de Pessoal de Nível Superior (Capes) seja exigida a obrigatoriedade de cumprimento de alguma atividade docente ao longo do processo de formação, o chamado Estágio de Docência, regulamentado pela Portaria n. 76/2010 da Capes, na prática e sob a perspectiva da experiência de alguns dos autores deste texto atuantes em cursos da saúde, essa atividade acrescenta muito pouco aos conhecimentos pedagógicos do pós-graduando da forma como comumente vem sendo aplicada. 
Embora os estudos sobre o Estágio de Docência sejam pouco numerosos, ${ }^{55}$ baseados na vivência de dois dos quatro autores deste texto que atuam na saúde e também são oriundos de pós-graduações da área da saúde e biológicas, podemos afirmar que nesse campo essa prática de estágio tem se restringido a atividades geralmente desenvolvidas: na forma de acompanhamento de algumas aulas teóricas ou práticas; na ministração de alguns conteúdos específicos dentro de uma disciplina sob a responsabilidade do orientador; na forma de monitoria em plantão de dúvidas; na forma de seminários ministrados ou assistidos no próprio programa de pós-graduação. Defendemos que o Estágio de docência, idealmente, deveria ser desenvolvido por meio do acompanhamento do pós-graduando ao longo de todo o processo de organização e ministração de uma disciplina, desde a elaboração do conteúdo programático e cronograma de execução até o fechamento de notas finais, de preferência em alguma disciplina não ministrada pelo seu orientador acadêmico.

Outro modelo de aplicação é o da Universidade de São Paulo, que instituiu o Programa de Aperfeiçoamento de Ensino (PAE) nos seus diversos institutos e na unidade de pós-graduação (PAE/USP, 2010). Entretanto, o PAE é um programa de participação eletiva/opcional aos pós-graduandos da Universidade, com exceção dos bolsistas de doutorado da Capes, portanto, não é realizado pela totalidade de alunos.

Os benefícios do Estágio docente, quando devidamente organizado e orientado na prática docente do pós-graduando que almeja a carreira acadêmica, são relatados por Barbosa et al. (2011, p. 31) ao cursarem a disciplina Estágio de Docência dentro do Programa de Pós-graduação em Enfermagem e Saúde da Universidade Estadual do Sudoeste da Bahia:

A execução de cada uma das nossas atribuições enquanto estagiárias/mestrandas/docentes proporcionou-nos uma oportunidade de inter-relação que foi além de conteúdos e planos. Excedeu inclusive a nossa própria expectativa, uma vez que tivemos que lançar mão de ferramentas adequadas ao exercício da docência, as quais nos instrumentalizaram para lidar com os desafios que surgiram e que, certamente, permeiam o processo ensino-aprendizagem percebido pelos que já estão na docência e também pelos que pretendem ingressar nela.

Em um estudo realizado por Castanho (2002), em que entrevistou professores de cursos da área da saúde quanto às diversas questões relativas à prática do ensino, um dos entrevistados salientou que “[...] sofre-se por não ter didática, estar diante

\footnotetext{
${ }^{5}$ Em uma busca avançada no banco de teses e dissertações da Capes, utilizando como estratégia de busca os termos Estágio Docência e Estágio docente, somente dois trabalhos foram identificados dentro dessa temática até o ano 2012. Ainda assim, tais trabalhos não estavam relacionados à área da saúde.
} 
do aluno e não ter didática." (informação verbal). Esta é uma fala que explicita a aflição de muitos docentes que não se sentem preparados para o seu ofício diário. Essa aflição geralmente é consequência da carência didática, o que, na maioria das vezes, é também fortemente percebida pelo corpo discente, conforme relata Santos (2013) ao entrevistar alunos de curso de graduação em Enfermagem e obter suas percepções sobre diversos aspectos do processo educacional da sua instituição:

\begin{abstract}
Alguns professores precisam melhorar a didática do ensino [...]; não transmitem de forma clara o conteúdo, ficam presos à leitura dos slides o que dificulta a compreensão da aula [...]; Às vezes existe um grande número de aulas expositivas o que acaba ficando cansativo para os discentes e prejudicando o processo de ensino-aprendizagem. (SANTOS, 2013, p. 4-6).
\end{abstract}

Outro aspecto importante dentro das aulas teórico-expositivas diz respeito ao seu tempo e sua duração. Da experiência pessoal desses autores, o que se tem visto é que há uma preocupação algumas vezes exacerbada por parte dos docentes com o tempo da aula expositiva, mais do que com as abordagens ou metodologias que serão aplicadas ao longo da aula para que o aluno desenvolva a sua aprendizagem. Isso revela claramente a carência de conhecimento sobre estratégias de ensino, porque é uma opinião quase unânime entre os docentes e entre especialistas de que uma aula teórica que rompe o tempo de 50 minutos seguidos sem intervalo deixa de ser produtiva do ponto de vista do aprendizado (TOKUHAMA-ESPINOSA, 2010).

Recentemente, o Programa Ciência sem Fronteiras do Governo Federal (CIÊNCIA SEM FRONTEIRAS, 2014), que tem por objetivo o intercâmbio científico de graduandos brasileiros em universidades internacionais nas áreas tecnológicas, realizou o Encontro de Orientações para Bolsistas, no qual novos bolsistas receberam orientações gerais, e também foram ouvidas experiências de bolsistas regressos. $\mathrm{O}$ discurso da maioria dos bolsistas que retorna de universidades internacionais consideradas "de ponta", como algumas nos Estados Unidos da América, Austrália e Europa, é de que a carga horária de aulas expositivas é bem menor do que nas universidades brasileiras. Entretanto, isso não quer dizer que os discentes ficam com o tempo livre nessas instituições, mas, sim, que são exigidos e estimulados a dedicarem maior tempo à leitura, à resolução de exercícios e aos estudos de situações reais (CIÊNCIA SEM FRONTEIRAS, 2014; RIGHETTI, 2013). Todas essas informações já acenderam o alerta na Capes da necessidade de mudanças no sistema de gestão do ensino superior brasileiro, sendo alvo de discussão pelo seu Presidente, Jorge Almeida Guimarães, na última reunião da Sociedade Brasileira para o Progresso da Ciência (SBPC) na Cidade 
de Recife em 2013, que ressaltou algumas das dificuldades de implantação de medidas reducionistas de carga horária nas instituições de ensino brasileiras.

Mas à parte dessa questão, e ainda nessa perspectiva, enquadra-se outra intervenção importante que a Didática, enquanto domínio de conhecimento teórico-prático sobre o ensino, pode propiciar ao docente da área da saúde, ou seja, como tornar dois tempos de 50 minutos ou, algumas vezes, até mesmo quatro tempos de 50 minutos por semana um ambiente não cansativo, não enfadonho, não repetitivo, mas de crescimento e aprendizado mútuo, de troca de experiências profissionais, de solidificação do conteúdo aprendido, de surgimento e esclarecimento de dúvidas? Essas são algumas das contribuições que a Didática, definida não somente, mas prioritariamente, como base de conhecimento para organizar o ensino, pode proporcionar ao docente da área da saúde.

\subsection{AULAS PRÁTICAS: ESSENCIAIS OU COMPLEMENTARES?}

O conceito de aulas práticas é bastante amplo e possui múltiplas dimensões dentro do Ensino Superior nas diversas carreiras. Por exemplo, a elaboração de um seminário, a discussão em grupo de uma situação real ou mesmo um caso clínico podem ser consideradas aulas práticas dentro de alguns contextos. Nos cursos de graduação da saúde, muitas dessas estratégias citadas são complementares às aulas teóricas, porque são realizadas em sala de aula, sob a supervisão do professor.

A aula prática, na perspectiva dos cursos da área da saúde, geralmente envolve uma ambientação laboratorial, ambulatorial, ou outra atividade na qual o aluno tenha contato real com as atividades executadas dentro da profissão escolhida. Convém ressaltar que essa perspectiva não é restritiva, mas baseada na experiência vivenciada ao longo dos anos de formação em saúde de dois dos autores deste texto. Portanto, espera-se que em uma aula prática de anatomia humana o aluno seja estimulado a conhecer as estruturas que compõem o corpo humano por meio do toque, do exame, da medição, interagindo com peças anatômicas, sejam naturais, sejam sintéticas. Assim como se espera que em uma aula prática de diagnóstico laboratorial do vírus HIV (vírus da imunodeficiência humana) o aluno possa realizar parcial ou integralmente as técnicas necessárias ao diagnóstico, ou seja, tenha acesso a informações práticas do tipo: qual amostra biológica será utilizada? Qual o método empregado e suas características técnicas? Quais os possíveis interferentes? Como se interpreta o resultado obtido? Seria possível elencar algumas dezenas de exemplos de aulas práticas nos diversos cursos da saúde, porém, em suma, trata-se de uma aula com forte 
caráter de manuseio experimental pelos discentes, seja individual, seja em grupo, sob a supervisão do professor responsável.

A questão de essencialidade das aulas práticas, com essa abordagem, nas disciplinas curriculares dos cursos da saúde, é traduzida pelo fato de que o aluno egresso, ao terminar o seu curso, estará habilitado ao exercício de uma determinada profissão e terá habilitação técnica. Na maior parte das vezes, o exercício dessa profissão está diretamente associado a procedimentos que poderão ser aplicados em seres humanos, e, por força dessa importância, não se podem negligenciar o treinamento e a capacitação prática mínima exigida para um procedimento específico, em que a vida humana está em questão. Por essa razão, além das aulas práticas, é também recomendada pelo Ministério da Educação, e exigida pelos conselhos regulamentadores de cada profissão, uma quantidade de horas mínimas de formação prática, cumpridas por meio do estágio curricular supervisionado, para que o formando obtenha uma habilitação na área.

O desenvolvimento de uma aula prática adequada, invariavelmente, passa pela experiência profissional do professor. O sucesso no desempenho de determinada profissão além dos muros da universidade é notavelmente reconhecido pelos alunos no professor em exercício da docência. No trabalho de Lazzarin, Nakama e Cordoni Junior (2007) sobre o papel do professor na percepção dos alunos de Odontologia mais uma vez aparece o conceito do "professor marcante", mas dessa vez relacionado ao modelo de sucesso social no exercício da sua atividade profissional. Nesses casos, são desenvolvidos sentimentos de maior admiração e respeito pelo docente. É salutar esclarecer que essas são situações quase específicas das carreiras de Medicina e Odontologia, nas quais os professores e profissionais médicos e odontólogos, por possuírem uma carreira que tradicionalmente alcança uma boa remuneração, optam por exercer a docência em regime específico, por exemplo, em regime de dedicação parcial nas instituições públicas e/ou horistas nas instituições privadas, podendo paralelamente atuar na profissão de origem. Ainda nesse contexto, o professor sob esse regime comumente atua nas disciplinas do ciclo/eixo formativo e essencialmente práticas, ou mesmo como preceptores nos estágios curriculares, e o aluno sob sua responsabilidade convive na rotina da sua profissão, o que torna o terreno muito mais fértil para o exercício da docência.

Salvos os dois casos citados, essa não é a realidade da maior parte dos docentes nas instituições de ensino, principalmente nas instituições públicas. Os professores do magistério superior em tais instituições, nos demais cursos da saúde e aqueles que atuam nas disciplinas do ciclo básico, são contratados em regime de dedicação 
exclusiva, em que legalmente estão proibidos por lei de exercer paralelamente outra atividade profissional. Em contrapartida, além das aulas ministradas, esses professores participam ativamente de projetos de pesquisa, extensão e atuam na pós-graduação nos programas de mestrado e doutorado. Essas atividades, com raríssimas exceções, não guardam relações diretas com a prática do exercício profissional. E, consequentemente, quanto mais afastado o professor se mantém da rotina prática da sua profissão, menor será seu leque de opções para o ensino do conhecimento profissional. A situação é ainda mais agravada quando o futuro docente finaliza a sua graduação, ingressa no mestrado e no doutorado de forma contínua e, em seguida, é “lançado" para a docência. Ou seja, seu conhecimento profissional ficou restrito ao estágio curricular mínimo obrigatório exigido para a finalização do seu curso.

Obviamente, essas são situações nas quais as mudanças na estrutura atual não dependem apenas do profissional-docente, visto que são determinadas por políticas educacionais e por legislações que regem a profissão. Entretanto, não se pode se abster de reconhecer a importância que o estabelecimento de contatos e parcerias com os profissionais em atividade possui na busca de um ensino contextualizado com o objetivo de manter a atividade de docência em consonância com o exercício real da profissão, ainda que o próprio docente não exerça aquela atividade fim. E o estímulo necessário para isso deve ser oriundo da autopercepção do docente quanto à necessidade de melhor qualificar a sua atividade de docência. Embora o corpo discente possa inicial e indiretamente contribuir para esse estímulo, por meio da percepção do docente a respeito da receptividade dos alunos em uma dada disciplina ou em um dado conteúdo, é fundamental que esse processo de autoavaliação seja de origem interna e individual, ou seja, uma metacognição da sua prática. Nesse processo, o professor poderá e deverá exercitar uma visão externa da sua própria atividade, anotando e analisando criticamente as situações em que uma dada proposta metodológica tenha alcançado o objetivo fim, elencando as razões do êxito, mas, principalmente, analisando e reformulando os seus pontos negativos. O objetivo final da atividade docente é o aprendizado do aluno, e, nessa perspectiva, a Didática fornece um conjunto de ferramentas para a construção dos caminhos percorridos ao longo dessa atividade. Considerando o que foi analisado em termos de conceitos, teorias e práticas exercidas pelos docentes da área da saúde, é possível observar o caráter dinâmico dessas situações, em que os atores e suas interações com o ambiente dos processos de ensino e aprendizagem sofrem mudanças contínuas. Portanto, a Didática não deverá ser pensada como uma espécie de receita infalível para a formação do bom professor. Deve-se ter em mente que este é um meio de constante adaptação, ou seja, o conjunto de estratégias 
desenvolvidas em um determinado semestre letivo pode não ser necessariamente o melhor para o semestre seguinte e assim por diante. Sobretudo, é importante que o docente seja capaz de mobilizar diferentes ferramentas desse conjunto para realizar as adaptações necessárias, e, para isso, é fundamental que exista uma fonte da qual essas ferramentas possam ser extraídas.

O professor de ensino superior de curso das áreas da saúde deve ter consciência que a didática instrumental, conforme Pimenta e Anastasiou (2010) definem, essa conjunção de ferramentas metodológicas, também não deve ser o único ancoradouro do processo de ensino, pois como uma atividade complexa de relações humanistas, está sujeita às modificações de tempo e espaço. Essas mesmas autoras, no livro Docência no Ensino Superior, definem o papel da Didática de forma muito contundente, relacionando tudo que foi descrito anteriormente:

[...] a tarefa da Didática é de compreender o funcionamento do ensino em situação, suas funções sociais, suas implicações estruturais; realizar uma ação autorreflexiva como componente do fenômeno que estuda [...] pôr-se em relação e diálogo com outros campos de conhecimentos construídos e em construção [...] proceder a constantes balanços críticos do conhecimento produzido no seu campo [...] para dele se apropriar e criar novos diante das novas necessidades que as situações de ensinar produzem. (PIMENTA; ANASTASIOU, 2010, p. 49).

A habilidade de transitar, além de manusear adequadamente, entre as distintas ferramentas disponíveis no campo da Didática para o exercício da docência, considerando os muitos fatores envolvidos, como a heterogeneidade do público-alvo, as adequações do assunto abordado, o tempo de exposição em aula, as dificuldades inerentes à transmissão de determinados conteúdos, pode ser analogicamente comparada a uma atuação artística, e, por essas razões, foi definida por Perissé (2011) como "a arte de ensinar", e é característica de um professor bem-sucedido.

Quadros e Montimer (2014) realizaram uma análise dos fatores que tornam um professor bem-sucedido, sob o ponto de vista dos alunos, baseados em um caso real de um professor de Química, bacharel em Química, com Pós-graduação em Química, mas sem contato anterior sistematizado com questões didáticas. ${ }^{66}$ Ao elencar as estratégias utilizadas pelo referido professor, verifica-se que são traduções das ferramentas preconizadas pela Didática, que também coadunam os saberes definidos

\footnotetext{
${ }^{6}$ A área da química, dentro da perspectiva deste texto, foi considerada pelos autores como correlata à área da saúde, pois foram considerados fatores comuns às áreas como a abstração de alguns conceitos teóricos, a utilização de aulas práticas e a necessidade constante de recorrer a sentidos figurados para esclarecimentos de conceitos.
} 
por Tardif (2000) e Cunha (2010), por exemplo: investiga concepções prévias (saber relacionado ao conhecimento do contexto sócio-histórico dos alunos), assumindo, ainda, a teoria da aprendizagem significativa de Ausubel (MOREIRA, 2006); cria momentos de descontração e de reflexão (saber relacionado à ambientação favorável à aprendizagem); valoriza os comentários dos estudantes (saber relacionado aos métodos de avaliação do desenvolvimento da aprendizagem); navega entre o discurso narrativo dialógico e de autoridade, fazendo uso da narrativa (saber relacionado à condução da aula alternando as múltiplas possibilidades da exposição); permite que os alunos conduzam a aula (saber relacionado ao reconhecimento do papel das partes envolvidas, ou seja, "o aluno no protagonismo do processo e o professor no papel de mediador do processo"). Todas essas características também coadunam com aquelas elencadas por Castanho (2001) como definição do "professor marcante". Entretanto, convém ressaltar que não se caracteriza uma receita de sucesso inquestionável ou infalível. Contudo, quando relatadas e verificadas quanto à sua eficiência em aplicações práticas do cotidiano da atividade docente, essas características poderão ser utilizadas como modelo de apoio para que cada profissional docente seja instigado a repensar o exercício da sua atividade "ser professor" ou a criação e o desenvolvimento de novas estratégias, sempre contextualizadas ao cotidiano profissional de cada docente, a cada corpo discente, a cada instituição, etc. Dessa forma, é possível vivenciar o conceito da “ensinagem”, expressão inicialmente explicitada por Anastasiou (1998) para definir o ensino com aprendizado efetivo decorrente da parceria professor-aluno, em um processo complexo, mas unificado, no qual o exercício de ensinar está indissociavelmente atrelado ao ato de aprender (LIBÂNEO, 2012; ROLDÃO, 2007).

\section{CONSIDERAÇÕES FINAIS}

Para encerrar esse texto, ressaltamos que as mudanças entendidas como necessárias na perspectiva da docência no ensino superior, particularmente dos cursos da área da saúde, em razão da sua particularidade técnica, têm como objetivo tornar os processos de ensino e de aprendizagem ("ensinagem") que ocorrem nas disciplinas de graduação, uma das partes integrantes da carreira do professor universitário, algo efetivamente voltado à construção conjunta do conhecimento, fruto de uma relação de crescimento concomitante professor-aluno. Uma construção conjunta dessa natureza não reduz nem anula a autoridade do professor no sentido de ser aquele que domina o conhecimento sobre um determinado assunto, mas é salutar que essa autoridade seja traduzida também na habilidade e na competência do professor em compartilhar esse 
conhecimento fazendo uso das diversas ferramentas didáticas, além dos conhecimentos pedagógico e metodológico adaptados ao seu público.

\section{REFERÊNCIAS}

ALMEIDA, E. G.; BATISTA, N. A. Desempenho docente no contexto PBL: essência para aprendizagem e formação médica. Revista Brasileira de Educação Médica, v. 37, n. 2, p. 192-201, 2013.

ALMEIDA, M. J. et al. Implantação das Diretrizes Curriculares Nacionais na graduação em Medicina no Paraná. Revista Brasileira de Educação Médica, v. 31, n. 2, p. 156-165, 2007.

ANASTASIOU, L. G. C. Metodologia do Ensino Superior: da prática docente a uma possível teoria pedagógica. 1. ed. Curitiba: IBPEX, 1998.

BARBOSA, A. S. et al. Práticas docentes no ensino superior: relato de experiência em estágio de docência. Revista Eletrônica do Mestrado Profissional em Ensino de Ciências da Saúde e do Ambiente (REMPEC) - Ensino, Saúde e Ambiente, v. 4, n. 1, p. 18-33, 2011.

BELEI, R. A.; GIMENIZ-PASCOAL, S. R.; NASCIMENTO, E. N. História curricular dos cursos de graduação da área da saúde. História da Educação, ASPHE/FaE/ UFPel, v. 12, n. 24, p. 101-120, 2008.

BRASIL. Lei n. 9.394, de 20 de dezembro de 1996. Casa Civil - Subchefia para assuntos jurídicos. Lei de Diretrizes e Bases da Educação Nacional. Estabelece as Diretrizes e Bases da Educação Nacional. Diário Oficial União, Brasília, DF, 23 dez. 1996.

CASTANHO, M. E. Professores de Ensino Superior da área da Saúde e sua prática pedagógica. Interface Comunicação, Saúde, Educação, v. 6, n. 10, p. 51-62, 2002.

CASTANHO, M. E. Sobre professores marcantes. In: CASTANHO, S.; CASTANHO, M. E. (Org.). Temas e textos em metodologia do ensino superior. 1. ed. Campinas: Papirus, 2001. p. 153-164.

CECCIM, R. B.; FEUERWERKER, L. C. M. Mudança na graduação das profissões de saúde sob o eixo da integralidade. Cadernos de Saúde Pública, v. 20, n. 5, p. 1400-1410, 2004.

CIÊNCIA SEM FRONTEIRAS. Programa Ciências sem Fronteiras. Novos bolsistas do Ciência sem Fronteiras recebem orientações para experiência no exterior. 2014. Disponível em: <http://www.cienciasemfronteiras.gov.br/web/csf/views/-/ journal_content/56_INSTANCE_VF2v/214072/4769323>. Acesso em: 27 jun. 2015. 
CUNHA, M. I. A docência como ação complexa. In: CUNHA, M. I (Org.). Trajetórias e lugares da docência universitária: da perspectiva individual ao espaço institucional. 1. ed. Araraquara: Junqueira \& Marins, 2010.

CUNHA, M. I. Docência na universidade, cultura e avaliação institucional: saberes silenciados em questão institucional: saberes silenciados em questão. Revista Brasileira de Educação, v. 11, n. 32, p. 358-371, 2006.

\section{EDUCASAÚDE. Núcleo de Educação, Avaliação e Produção Pedagógica em}

Saúde. Disponível em: <www.educasaude.org>. Acesso em: 27 jun. 2015.

LAZZARIN, H. C.; NAKAMA, L.; CORDONI JUNIOR, L. O papel do professor na percepção dos alunos de odontologia. Saúde e Sociedade, v. 16, n. 1, 2007.

LIBÂNEO, J. C. Didática: velhos e novos temas. Goiânia: Edição do Autor, 2002.

LIBÂNEO, J. C. Ensinar e aprender, aprender e ensinar: o lugar da teoria e da prática em didática. In: LIBÂNEO, J. C.; ALVES, N. (Org.) Temas de Pedagogia: diálogos entre didática e currículo. 1. ed. São Paulo: Cortez, 2012. p. 36-60.

LOPES, A. O. Aula expositiva: superando o tradicional. In: VEIGA, I. P. A. (Org.). Técnicas de ensino: Por que não? 12. ed. Campinas: Papirus, 2001. p. 35-48.

MASETTO, M. T. Docência universitária: repensando a aula. In: TEODORO, A. (Org.). Ensinar e aprender no ensino superior: por uma epistemologia pela curiosidade da formação universitária. 1. ed. São Paulo: Cortez Mackenzie, 2003. p. 79-108.

MINISTÉRIO DA EDUCAÇÃO. Pesquisa avaliará oportunidade de emprego obtida por egressos. 2014. Disponível em: <http://portal.mec.gov.br/index.php?v iew $=$ article $\&$ catid $=212 \% 3$ Aeducacao-superior $\& i d=20638 \% 3$ Apesquisa-avaliara-oportunidade-de-emprego-obtida-por-e\%E2\%80\%A6>. Acesso em: 27 jun. 2015.

MOREIRA, M. A. A Teoria da Aprendizagem Significativa e sua implementação em sala de aula. 1. ed. Brasília, DF: Universidade de Brasília, 2006.

PAE/USP. Diretrizes do Programa de Aperfeiçoamento de Ensino, 2010. Disponível em: $<$ http://www.prpg.usp.br/wp-content/uploads/diretrizes_PAE_-09.12.10. pdf $>$. Acesso em: 27 jun. 2015.

PERISSÉ, G. A arte de ensinar. 2. ed. São Paulo: Saraiva, 2011.

PIMENTA, S. G.; ANASTASIOU, L. G. C. Docência no ensino superior. 4. ed. São Paulo: Cortez, 2010. 
QUADROS, A. L.; MORTIMER, E. F. Fatores que tornam o professor de Ensino Superior bem-sucedido: analisando um caso. Ciência e Educação, Bauru, v. 20, n. $1,2014$.

RIGHETTI, S. Universidades de ponta têm menos aulas. Folha de São Paulo, São Paulo, 17 out. 2013. Disponível em: <http://abecedario.blogfolha.uol.com. br/2013/10/17/universidades-de-ponta-tem-menos-aulas/>. Acesso em: 27 jun. 2015.

ROLDÃO, M. C. Função docente: natureza e construção do conhecimento profissional. Revista Brasileira de Educação, v. 12, n. 34, 2007.

ROZENDO, C. A. et al. Uma análise das práticas docentes de professores universitários da área de saúde. Revista Latino-americana de Enfermagem, v. 7, n. 2, p. 15-23,1999.

SANTOS, V. C. et al. A prática docente no ensino superior sob a ótica de formandos de enfermagem. EFDeportes.com, Revista Digital. Buenos Aires, año 18, nº 183, 2013. Disponível em: <http://www.efdeportes.com/efd183/a-pratica-docente-no-ensino-superior.htm>. Acesso em 27 jun. 2015.

SILVA, D. S.; ALENCAR, E. M. L. S. O docente da educação superior na área de saúde: formação, satisfação e práticas pedagógicas. Educação em Destaque, v. 3, n. 2, p. 12-27, 2010.

SOARES, L. S. L. Professores universitários da área de saúde da FACIME/UESPI: Uma análise de suas práticas docentes. In: ENCONTRO DE PESQUISA EM EDUCAÇÃO DA UFPI, 4., 2006, Teresina. Anais... Teresina, 2006. Disponível em: <http://www.ufpi.br/subsiteFiles/ppged/arquivos/files/eventos/2006.gt1/ GT1_18_2006.PDF>. Acesso em: 27 jun. 2015.

TARDIF, M. Saberes profissionais dos professores e conhecimentos universitários: elementos para uma epistemologia da prática profissional dos professores e suas consequências em relação à formação para o magistério. Revista Brasileira de Educação, n. 13, p. 5-20, 2000.

TOKUHAMA-ESPINOSA, T. The new science of teaching and learning: using the best of mind, brain, and education science in the classroom. 1. ed. New York: Teachers College Press, 2010.

Aceito em: 09 de agosto de 2016 Recebido em: 28 de novembro de 2016

Endereço para correspondência: Avenida Carlos Chagas Filho, 373, Centro de Ciências da Saúde, Bloco I, Sala I-53, 21941-902, Cidade Universitária, Rio de Janeiro, Rio de Janeiro, Brasil; renatacampos@micro.ufrj.com 